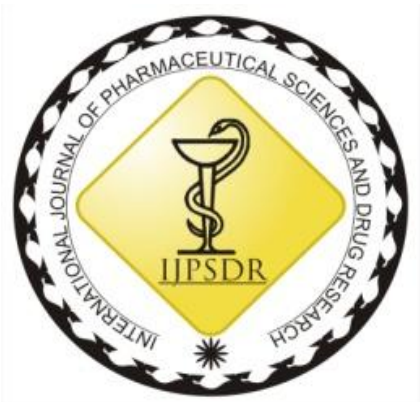

\author{
RESEARCH ARTICLE
}

ISSN: 0975-248X CODEN (USA): IJPSPP

$(\mathrm{Cc})$ EY-No-SA

\title{
Formulation and Development of Gastroretentive Drug Delivery System of Efavirenz
}

\author{
Monica RP Rao*, Pooja B. Karanjkar \\ Department of Pharmaceutics, AISSMS College of Pharmacy, Savitribai Phule Pune University, Kennedy Road, \\ Near R.T.O, Pune-411001, Maharashtra, India
}

Copyright (C) 2019 M Rao et al. This is an open access article distributed under the terms of the Creative Commons Attribution-NonCommercialShareAlike 4.0 International License which allows others to remix, tweak, and build upon the work non-commercially, as long as the author is credited and the new creations are licensed under the identical terms.

\begin{abstract}
Efavirenz, a non-nucleotide reverse transcriptase inhibitor is an important drug for treating patients with Human Immunodeficiency Virus infections. It belongs to BCS class II have low solubility and poor intrinsic dissolution rate. It is highly basic (pKa 10.2) which makes it suitable candidate for floating dosage form for continuous delivery in stomach.The study was aimed to improve the solubility by solid dispersion technique.Saturation solubility study and drug content were evaluated for solid dispersion preparation. Saturation solubility shows 8 fold increases in $0.1 \mathrm{~N}$ HCL compared to plain drug and drug content was found to be between 95\%-102\%. Further effervescent floating gastroretentive drug delivery system was prepared by $3^{2}$ full factorial design with independent variables i.e., concentration of HPMC K100 as matrix forming agent and citric acid as gas generating agent. Lag time, floating time, percent drug release were studied as responses. The optimized batch exhibited floating lag time of 40 sec and the in vitro release studies showed $89.5 \%$ drug release in $9 \mathrm{~h}$ and tablet remained floating for greater than $8 \mathrm{~h}$. The study thus demonstrated that solubility is increased by solid dispersion technique and floating delivery systems may increase solubility and bioavailability of Efavirenz.
\end{abstract}

Keywords: Efavirenz, GRDDS, Solid dispersion (SD), Solvent evaporation method, Solubility enhancement, Percent drug release.

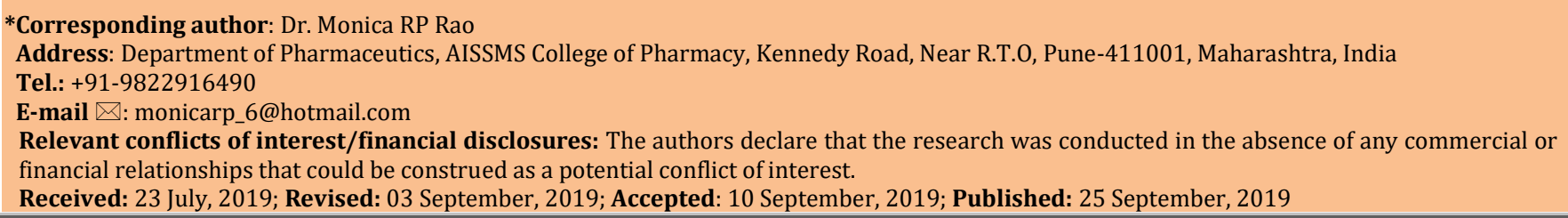

\section{INTRODUCTION}

Controlled drug delivery systems are recognized as important pharmaceutical systems that have made major inroads in dosage form design. Drugs which have short half-lives are absorbed in gastrointestinal tract (GIT) without any difficulty and also eliminated from the systemic circulation. [1] To obtain desired therapeutic effect, repeated dosing of the drugs is essential. Oral controlled release formulations enable this limitation to be overcome by slow release of the drug in the GIT and maintain sufficient plasma drug concentration for required time span. [2] Gastric retention devices are intended to prolong the gastric residence time of oral controlled release dosage forms. This results in increased residence time and hence absorption of drugs that act locally. Drugs that have 
specific absorption windows in GIT and drugs less soluble in the intestinal fluid are also suitable candidates for gastro retention. ${ }^{[3]}$ Many strategies are available to prolong gastric residence time which includes bioadhesive systems, swelling and expanding systems and floating systems. Among all methods floating drug delivery system enables easy and practical technique to obtain gastroretention. ${ }^{[4]}$ Floating dosage form has density less than that of gastric fluids and consequently remains a float in the stomach contents to lengthen the gastric retention time. ${ }^{[5-9]}$

$\mathrm{HIV}$ is a retrovirus of the lentivirus family, which in particular destroys $\mathrm{CD} 4+\mathrm{T}$ cells that are important for proper functioning of the immune system. [9-10] The highly active antiretroviral treatment (HAART) has saved 2.8 million lives worldwide. Efavirenz (EFV) is an authorised first line HIV-1 non-nucleoside reverse transcriptase inhibitor (NNRTI) approved by The World Health Organisation (WHO) for the treatment of HIV. EFV is (S)-6-chloro-4 (cyclopropylethynyl)-1, 4dihydro-4-(trifluoromethyl)-2H-3, 1-benzoxazin-2-one. It attaches to and blocks the HIV enzyme called reverse transcriptase.It's a crystalline powder, non-hygroscopic, sour in taste and insoluble in water, protein-binding of $>99 \%$ and poor oral bioavailability (40-50\%). It belongs to BCS (Biopharmaceutical classification system) class II drug having low aqueous solubility $(4 \mu \mathrm{g} / \mathrm{ml})$, poor intrinsic rate of dissolution $\left(0.037 \mathrm{mg} / \mathrm{cm}^{2} / \mathrm{min}\right)$. It is highly basic with $\mathrm{pKa}=10.2$ and lipophilic with $\log \mathrm{P}$ value of $5.4{ }^{[10]}$ which makes it suitable candidate forthe preparation of floating dosage form for continuous delivery of EFV in the stomach.

The aim of current work was to improve the solubility of EFV by solid dispersion technique and development, evaluation of stable GRDDS (Gastro retentive drug delivery system) formulation. Solid dispersion is among the successful and reliable techniques in which active pharmaceutical ingredients is dispersed in an inert polymeric carrier in solid state and it is prepared by using different method such as the melting, solvent evaporation and melting-solvent evaporation method. [11-12] Solid dispersions of EFV with HPMC E5 were prepared in different ratios to improve its solubility and dissolution rate. EFV solid dispersion (SD) was further incorporated into floating tablet to overcome the problems of oral absorption of drug. ${ }^{[2]}$ Effect of mixtures of various polymers and excipients on different physicochemical properties was evaluated. Full factorial design $\left(3^{2}\right)$ was used to develop optimized GRDDS using the floatation technology. The formulations were evaluated for floating time, floating lag time, percent drug release, and stability studies. In vitro dissolution kinetic studies were performed to assess the improvement in the solubility and dissolution rate of EFV. [13]

\section{MATERIALS AND METHODS}

Materials
EFV was gifted by Mylan Laboratories, Nashik, India. HPMC K100 Abitech Corporation (Columbus, OH, USA). Sodium bicarbonate was purchased from BASF Corporation 3000 Continental Drive - North Mount Olive, NJ 07828-1234. Citric acid, Poly vinyl pyrolidone k-30, Sodium carboxy methyl cellulose, Talc was purchased from Loba Chemicals, Mumbai, India. Hydrochloric acid $(\mathrm{HCl})$ was purchased from Merck Specialities, Mumbai, India. Methanol, acetonitrile, and water of high performance liquid chromatography (HPLC) grade were used in UV spectrophotometer studies purchased from Merck, Mumbai, India. Freshly prepared double distilled water was used whenever required.

Methods

\section{Preparation of solid dispersions}

Preliminary trials were conducted to select the polymer for SD which included HPMC E5, Eudragit RS 100 and Soluplus in different ratios. Solvent evaporation method was used to prepare solid dispersions. Different solvent systems were used depending on solubility of the components of the mixtures. The solvents were evaporated using electric water bath and subsequently the moist mass was dried at room temperature. ${ }^{[14]}$ The samples were triturated until a soft powder was obtained using a mortar and pestle and which was then passed through sieve no. 22 of $150 \mu \mathrm{m}$ pore size. These samples were evaluated for saturation solubility. [15] Based on the increase in solubility further studies were conducted with HPMC as polymer as it produced greater increase in EFV solubility than other polymers. Hence 03 ratios of drug: HPMC E5 were used to prepare SD1 (1:1), SD2 (1:0.75) and SD3 (1:0.5).

\section{Evaluation of solid dispersions \\ Drug content}

The percentage drug content in SDs was estimated by dissolving $20 \mathrm{mg}$ of SD in methanol and filtered. The filtrate was diluted with methanol and drug content was determined against blank by UV spectrophotometer (Jasco V-730) at $247 \mathrm{~nm}$. [16-17]

\section{Saturation solubility studies}

Saturation solubility was determined by adding excess drug/binary SD into $20 \mathrm{ml}$ of $\mathrm{DW}, 0.1 \mathrm{~N} \mathrm{HCl}$, separately and were placed in an orbital shaker (CIS-24 Remi, India) at $37 \pm 0.5^{\circ} \mathrm{C}$ for $24 \mathrm{~h}$. The equilibrated suspensions were centrifuged and filtered through Whatman filter paper $(0.45 \mu \mathrm{m})$ and analysed for drug content by UV-spectrophotometer (Jasco V-730) at 247 nm. [17]

\section{Dissolution test}

USP dissolution test apparatus (Lab India DS 8000) type II (Paddle) operating at $50 \mathrm{rpm}$ was used for the study. Dissolution of the drug and SDs was performed in triplicate. SDs equivalent to $200 \mathrm{mg}$ of the EFV were subjected to these studies in $900 \mathrm{ml}$ of $0.1 \mathrm{~N} \mathrm{HCl}$ as dissolution media at $37 \pm 0.2^{\circ} \mathrm{C}$, respectively. The sample $(10 \mathrm{ml})$ of the dissolution media was removed at predetermined time intervals and was 
simultaneously analysed UV spectrophotometrically at a $\lambda$ max of $247 \mathrm{~nm}$. The SDs i.e, SD1, SD2, SD3 which displayed the most increase in saturation solubility and dissolution rate was subjected to further evaluation. ${ }^{[18]}$

Micrometric flow property of solid dispersions

The various powder flow properties of solid dispersion like angle of repose, bulk density, tapped density; Hausner's ratio and Carr's index were evaluated. [19]

Fourier transform infrared (FT-IR) Spectroscopy

Fourier transform infrared spectra of powdered samples of EFV and SDs were obtained using a FTIR spectrophotometer (Jasco FTIR - 460 plus spectrophotometer). The scanning range was $400-4000$ $\mathrm{cm}^{-1}$ and the resolution was $2.4 \mathrm{~cm}^{-1}$. [20]

Differential Scanning Calorimetric Analysis (DSC)

The thermograms were recorded for EFV and SD using a differential scanning calorimeter. A heating rate $10^{\circ} \%$ min was employed in the $30-300^{\circ} \mathrm{C}$ temperature range. Samples were placed in aluminium sample pans and an empty pan was used as a reference standard. The analysis was performed on $5 \mathrm{mg}$ samples in a nitrogen atmosphere (40 ml/min). [21]

Powder X-ray diffraction study (PXRD)

The PXRD spectra of EFV and SD were recorded using high power powder X-ray diffractometer (Ru-200B). Cu was used as target filter and voltage/current of 40 $\mathrm{kV} / 40 \mathrm{~mA}$ was applied. The scan speed was $4 \theta / \mathrm{min}$. The samples were analyzed at $2 \theta$ angle range of $5^{\circ}-50$ o. Step time was $0.5 \mathrm{~s}$ and time of acquisition was $1 \mathrm{~h}$. [22]

Preparation of Floating Tablets with Solid Dispersion The solid dispersion which displayed greater increase in solubility was used for the formulation of gas generating floating tablets. HPMC K 100 a water soluble polymer was selected as a hydrophilic matrix. The solid dispersion and other tablet ingredients were individually passed through sieve \#60 and mixed thoroughly by triturating up to $15 \mathrm{~min}$. Then ethanol solution containing PVP K30 were added dropwise to above mixture \&the doughy mass was passed through sieve no 18. Granules were dried at room temperature. Further it was lubricated with talc. [23]

Experimental design

A $3^{2}$ full factorial design was used to formulate the tablets. The designs consist of two factors at three levels. Two factors i.e, HPMC K 100 (A) and citric acid (B) were evaluated each at three levels lag time (Y1), floating time (Y2), \% drug release (Y3)\& experimental trials were performed at all possible nine combinations.

\section{Characterization of factorial batches}

\section{Precompression evaluation parameters}

The various powder flow properties were evaluated like angle of repose, bulk density, tapped density, Hausner's ratio and Carr's index. [24]

Floating lag time

Floating lag time was determined by placing each tablet to the $100 \mathrm{ml}$ of $0.1 \mathrm{~N} \mathrm{HCl}$ in beaker. Time required for tablet to float was recorded. The experiment was conducted in triplicates. [25-26]
Table 1: Relationship between angle of repose $(\Theta)$ and flowability

\begin{tabular}{cc}
\hline Angle of Repose $(\boldsymbol{\theta})$ & Flowability \\
\hline$<25$ & Excellent \\
$25-30$ & Good \\
$30-40$ & Passable \\
$>40$ & Very Poor \\
\hline
\end{tabular}

\begin{tabular}{|c|c|c|c|c|c|c|c|c|}
\hline $\begin{array}{l}\text { S. } \\
\text { No }\end{array}$ & Ingredients & PT1 & PT2 & PT3 & PT4 & PT5 & PT6 & PT7 \\
\hline 1 & $\begin{array}{c}\text { Solid } \\
\text { dispersion }\end{array}$ & 400 & 400 & 400 & 400 & 400 & 400 & 400 \\
\hline 2 & HPMC & 19.34 & 19.34 & 24.34 & 24.34 & 19.34 & 19.34 & 19 \\
\hline 3 & $\begin{array}{c}\text { Sodium } \\
\text { bicarbonate }\end{array}$ & 147 & 117 & 132 & 132 & 80 & 80 & 100 \\
\hline 4 & Citric acid & 9.75 & 9.75 & 9.75 & 19 & 26 & 15.75 & 26.75 \\
\hline 5 & PVP K30 & 20 & 15 & 15 & 5 & 10 & 10 & - \\
\hline 6 & $\begin{array}{l}\text { Sodium } \\
\text { CMC }\end{array}$ & 25 & 100 & 50 & 50 & 100 & 100 & 75 \\
\hline 7 & Talc & 29.75 & 19.25 & 19.25 & 10 & 15.25 & 25.25 & 29.25 \\
\hline
\end{tabular}

\begin{tabular}{ccc} 
Table 3: & & \\
\hline S. No & Independent variable & Dependent variable \\
\hline 1 & HPMC & Floating time \\
2 & Citric acid & Lag time \\
& & Percent drug release in $8 \mathrm{~h}$. \\
\hline
\end{tabular}

Table 4: Actual \& coded levels of the factors

\begin{tabular}{|c|c|c|c|c|c|c|}
\hline \multirow{2}{*}{ Factor } & \multicolumn{3}{|c|}{ Actual values (mg) } & \multicolumn{3}{|c|}{ Coded values } \\
\hline & low & Mid & High & Low & Mid & High \\
\hline $\begin{array}{c}\text { Factor A } \\
\text { HPMC }\end{array}$ & 19.34 & 21.84 & 24.34 & -1 & 0 & 1 \\
\hline $\begin{array}{l}\text { Factor B } \\
\text { Citric acid }\end{array}$ & 19 & 22.5 & 26 & -1 & 0 & 1 \\
\hline
\end{tabular}

Table 5: Composition of the formulations in terms of coded values

\begin{tabular}{cccc}
\hline \multirow{2}{*}{ S. No } & \multirow{2}{*}{ Batch codes } & \multicolumn{2}{c}{ Coded factor levels } \\
\cline { 3 - 4 } & & X1 & X2 \\
\hline 1 & F1 & 1 & 1 \\
2 & F2 & 0 & 1 \\
3 & F3 & 1 & 1 \\
4 & F4 & 1 & 0 \\
5 & F5 & 0 & 0 \\
6 & F6 & 1 & 0 \\
7 & F7 & 1 & 1 \\
8 & F8 & 0 & 1 \\
9 & F9 & 1 & 1 \\
\hline
\end{tabular}

Table 6: Composition of formulations of optimization (all quantities in $\mathrm{mg}$ )

\begin{tabular}{ccccccccccc}
\hline $\begin{array}{c}\text { S. } \\
\mathbf{N} \\
\mathbf{o}\end{array}$ & $\begin{array}{c}\text { Ingredie } \\
\text { nts }\end{array}$ & $\mathbf{F 1}$ & F2 & F3 & F4 & F5 & F6 & F7 & F8 & F9 \\
\hline 1 & Solid & 400 & 400 & 400 & 400 & 400 & 400 & 400 & 400 & 400 \\
& $\begin{array}{c}\text { dispersi } \\
\text { on }\end{array}$ & & & & & & & & & \\
2 & HPMC & 21. & 19. & 21. & 21. & 19. & 24. & 19. & 24. & 24. \\
& & 84 & 34 & 84 & 84 & 34 & 34 & 34 & 34 & 34 \\
3 & Sodium & 80. & 59. & 80. & 77. & 80. & 54. & 77. & 80. & 51. \\
& bicarbon & 66 & 66 & 66 & 16 & 66 & 66 & 66 & 66 & 66 \\
& ate & & & & & & & & & \\
4 & Citric & 22. & 19 & 19 & 26 & 22. & 19 & 26 & 26 & 22. \\
& acid & 5 & & & & 5 & & & & 5 \\
& PVP K30 & 65 & 42 & 43. & 65 & 42. & 42 & 42 & 59 & 42 \\
& & & & 5 & & 5 & & & & \\
& Sodium & 50 & 100 & 75 & 50 & 75 & 100 & 75 & 50 & 100 \\
7 & CMC & & & & & & & & & \\
& Talc & 10 & 10 & 10 & 10 & 10 & 10 & 10 & 10 & 10 \\
\hline
\end{tabular}

Floating time

The tablets from optimised batch were placed in a 100 $\mathrm{ml}$ glass beaker containing $0.1 \mathrm{~N} \mathrm{HCl}$. The duration for which the tablets remained floating on the surface of medium was determined as floating time. [27]

In vitro dissolution studies 
The in vitro dissolution studies were carried out using USP apparatus type II (DA 8000, Lab India) in $0.1 \mathrm{~N}$ $\mathrm{HCl}(900 \mathrm{ml})$ at paddle speed of $100 \mathrm{rpm}$ at $37^{\circ} \mathrm{C} \pm$ $0.5^{\circ} \mathrm{C}$. Aliquots of $10 \mathrm{ml}$ of samples were withdrawn at $1 \mathrm{~h}$ interval till $8 \mathrm{~h}$ and analyzed by UV spectrophotometer at $247 \mathrm{~nm}$. The release studies were conducted and the values were plotted versus time with standard deviation of less than 3 , indicating the reproducibility of the results. [28]

\section{Post compression evaluation parameters}

Hardness, thickness, friability, drug content, uniformity of weight was evaluated for floating tablets. [23, 28]

\section{Optimization and validation model}

The drug release data and floating lag time was input in Design expert software 11.0 and polynomial equations were generated. Based on desirability function numerical optimization was done to generate the optimized formula. The optimized formulation predicted by the software was prepared and analysed to assess similarity with predicted responses.

\section{Stability studies}

Optimized floating tablet was subjected to physical stability studies for 3 months at $40^{\circ} \mathrm{C} \pm 75 \% \mathrm{RH}$ (Remi, CHM 6 S). Samples were evaluated for physical appearance, hardness, drug content and floating lag time. ICH Q1A (R2) guidelines were followed for stability studies. [23]

Table 7: IP standards of uniformity of weight

\begin{tabular}{ccc}
\hline S. No & Average Wt. of tablet & \% deviation \\
\hline 1 & $80 \mathrm{mg}$ or $<80$ & 10 \\
2 & $>80$ to $<250 \mathrm{mg}$ & 7.5 \\
3 & $>250$ or more & 5 \\
\hline
\end{tabular}

Table 8: Melting point of EFV

\begin{tabular}{ccc}
\hline Property & \multicolumn{2}{c}{ Observation } \\
\hline \multirow{2}{*}{ Melting point } & Reported & Observed \\
\cline { 2 - 3 } & $139-1411^{\circ} \mathrm{C}$ & $138-140^{\circ} \mathrm{C}$ \\
\hline
\end{tabular}

Table 9: Linearity of plain EFV in methanol AR Grade $(\mathrm{N}=3$, Mean \pm SD)

\begin{tabular}{cc}
\hline Concentration $(\boldsymbol{\mu g} / \mathbf{m l})$ & Absorbance $(\mathbf{2 4 7} \mathbf{n m})$ \\
\hline 5 & $0.2611 \pm 0.001$ \\
10 & $0.4857 \pm 0.005$ \\
15 & $0.7272 \pm 0.0001$ \\
20 & $0.9654 \pm 0.0001$ \\
25 & $0.1985 \pm 0.0001$ \\
\hline
\end{tabular}

Table 10: Linearity validation data UV spectrophotometric analysis of $\operatorname{EFV}(\mathrm{N}=3$, Mean $\pm \mathrm{SD})$

\begin{tabular}{|c|c|c|c|c|}
\hline \multirow[b]{2}{*}{$\begin{array}{c}\text { Concentration } \\
(\mu \mathrm{g} / \mathrm{ml})\end{array}$} & \multicolumn{4}{|c|}{ Absorbance (247 nm) } \\
\hline & $\begin{array}{c}\text { Linearity } \\
1\end{array}$ & $\begin{array}{c}\text { Linearity } \\
2\end{array}$ & Linearity 3 & $\begin{array}{l}\text { Average } \pm \\
\text { SD }\end{array}$ \\
\hline 5 & 0.2611 & 0.261 & 0.2613 & $\begin{array}{c}0.2612 \pm \\
0.0002\end{array}$ \\
\hline 10 & 0.4857 & 0.4861 & 0.4862 & $\begin{array}{c}0.4756 \pm \\
0.0003\end{array}$ \\
\hline 15 & 0.7272 & 0.7273 & 0.7274 & $\begin{array}{c}0.7275 \pm \\
0.0001\end{array}$ \\
\hline 20 & 0.9654 & 0.9652 & 0.9654 & $\begin{array}{c}0.9653 \pm \\
0.0001\end{array}$ \\
\hline 25 & 1.1985 & 0.1987 & 1.1985 & $\begin{array}{c}1.1987 \pm \\
0.0001\end{array}$ \\
\hline $\mathrm{R}^{2}$ & 0.9999 & 0.9999 & 0.9999 & 0.9999 \\
\hline
\end{tabular}

Table 11: Interday precision data for UV spectrophotometric analysis of EFV

\begin{tabular}{cccc}
\hline $\begin{array}{c}\text { Concentration } \\
(\mathbf{\mu g} / \mathbf{m l})\end{array}$ & $\begin{array}{c}\text { Mean Absorbance* } \\
\mathbf{( 2 4 7} \mathbf{~} \mathbf{m})\end{array}$ & SD & \%RSD \\
\hline 5 & 0.2540 & 0.00011547 & 0.045 \\
10 & 0.4862 & 0.0002 & 0.0411 \\
\hline
\end{tabular}

Table 12: intraday precision data for UV spectrophotometric analysis of EFV

\begin{tabular}{cccc}
\hline $\begin{array}{c}\text { Concentration } \\
(\mathbf{\mu g} / \mathbf{m l})\end{array}$ & $\begin{array}{c}\text { Mean Absorbance* } \\
(\mathbf{2 4 7} \mathbf{~} \mathbf{m})\end{array}$ & SD & \%RSD \\
\hline 5 & 0.2538 & 0.000288 & 0.113 \\
10 & 0.4861 & 0.00023 & 0.047 \\
\hline
\end{tabular}

Table 13: Percent recovery data for UV spectrophotometric analysis of EFV

\begin{tabular}{cccccc}
\hline Level & $\begin{array}{c}\text { Concentrati } \\
\text { on } \\
(\boldsymbol{\mu} \mathrm{g} / \mathbf{m l})\end{array}$ & $\begin{array}{c}\text { Total } \\
\text { Concentrati } \\
\text { on } \\
(\boldsymbol{\mu g} / \mathbf{m l})\end{array}$ & $\begin{array}{c}\text { Mean } \\
\text { Absorbance* } \\
\text { SD }(\mathbf{2 4 7} \mathbf{~ n m})\end{array}$ & $\begin{array}{c}\text { Practical } \\
\text { Concentra } \\
\text { tion }\end{array}$ & $\begin{array}{c}\text { Recover } \\
\mathbf{y}(\%)\end{array}$ \\
\hline $50 \%$ & $10+5$ & 15 & 0.7273 & 14.98 & 99.86 \\
$100 \%$ & $10+10$ & 20 & 0.9653 & 20.08 & 100.4 \\
$150 \%$ & $10+15$ & 25 & 1.1986 & 24.99 & 99.98 \\
\hline
\end{tabular}

\section{RESULTS AND DISCUSSION}

\section{Preparation of Solid Dispersions}

Numbers of methods are used to prepare solid dispersions depending on the nature of drug and polymer. These include solvent evaporation, melt method, hot melt extrusion and gel entrapment method. [13] Melt method and melt extrusion method involve heating to melt the carriers and this may cause unwanted changes in the physicochemical profile of the drug such as degradation, crystallographic changes, etc. [17] Hence in present study solid dispersions of EFV were prepared by solvent evaporation method using different polymer i.e., HPMC E5, Eudragit RS 100 and Soluplus in three ratios i.e, (1:1) (1:0.75) (1:0.5) respectively. Different solvent systems were used depending on solubility of the components of the mixtures. In this method the drug is in molecular form resulting in an intimate mixture between drug and polymer. [14] Solid dispersions were evaluated for saturation solubility \& percent drug release in $0.1 \mathrm{~N}$ $\mathrm{HCl}$. Saturation solubility and percent release showed an increase with increase in concentration of polymers. Solid dispersions i.e, A(Drug + HPMC E 5), B (Drug + Eudragit RS 100) and C (Drug + Soluplus) containing (1:1) ratio showed an almost 11 fold , 7 fold and 8 fold increase in solubility as compared to plain drug EFV respectively. From the study, it was found that all solid dispersions displayed higher release than plain drug. SD A showed nearly $89 \%$ release in $90 \mathrm{~min}$. SD B and SD C exhibited $77 \%$ and $73 \%$ release at $90 \mathrm{~min}$ respectively. All ratios of drug with HPMC E5 displayed higher solubility than SDs of other polymers in different ratios. Hence, the SD A i.e., A (Drug + HPMC E 5), was selected for further studies.

Micrometric properties of solid dispersions

The prepared solid dispersions were evaluated for micrometric properties. The angle of repose was found to be excellent thus pointing to excellent flow properties (Table 14) for all the dispersions prepared. However Hausner's ratio for SD2 and SD3 was found 
to be less than or equal to 1.15 which indicates presence of significant interparticle frictions. [18] Moreover, SDs having Carr's index below 15 were considered to have good flow properties and could be successfully compressed into tablets with uniform weight. [29]

\section{Drug content}

The percentage drug content was determined by UV/Visible spectrophotometer (Make Lab UV 3000) at $247 \mathrm{~nm}$. ${ }^{[29]}$ Drug content in all SDs was found to be between $95 \%-102 \%$ indicating no or negligible loss of drug during the process. [30]

\begin{tabular}{|c|c|c|c|c|c|}
\hline $\begin{array}{c}\text { Formula } \\
\text { code }\end{array}$ & $\begin{array}{l}\text { Angle of } \\
\text { repose }\left(^{\circ}\right)\end{array}$ & $\begin{array}{c}\text { Bulk } \\
\text { density } \\
(\mathrm{g} / \mathrm{ml})\end{array}$ & $\begin{array}{c}\text { Tapped } \\
\text { density } \\
(\mathrm{g} / \mathrm{ml})\end{array}$ & $\begin{array}{c}\text { Hausner } \\
\text { ratio }\end{array}$ & $\begin{array}{l}\text { Carr's } \\
\text { index }\end{array}$ \\
\hline SD1 & $\begin{array}{c}25.44 \pm \\
2.41\end{array}$ & $\begin{array}{c}0.440 \pm \\
0.12\end{array}$ & $\begin{array}{c}0.483 \pm \\
0.26\end{array}$ & $1.09 \pm 0.66$ & $\begin{array}{c}8.33 \pm \\
4.45\end{array}$ \\
\hline SD2 & $\begin{array}{c}30.96 \pm \\
3.12\end{array}$ & $\begin{array}{c}0.489 \pm \\
0.25\end{array}$ & $\begin{array}{c}0.558 \pm \\
0.23\end{array}$ & $1.16 \pm 0.2$ & $\begin{array}{c}12.54 \pm \\
3.5\end{array}$ \\
\hline SD3 & $\begin{array}{c}29.24 \pm \\
3.33\end{array}$ & $\begin{array}{c}0.464 \pm \\
0.18\end{array}$ & $\begin{array}{c}0.583 \pm \\
0.12\end{array}$ & $\begin{array}{c}1.256 \pm \\
0.45\end{array}$ & $\begin{array}{c}11.9 \pm \\
3.89\end{array}$ \\
\hline
\end{tabular}

Table 15: Saturation solubility of EFV in different solvent. Mean \pm SD (N=3)

\begin{tabular}{|c|c|c|c|c|c|}
\hline S. No & Media & Plain drug & SD 1 & SD 2 & SD 3 \\
\hline 1 & Water & $4.6 \pm 2.5$ & $34.19 \pm 2.3$ & $32.54 \pm 2.8$ & $29.6 \pm 2.5$ \\
\hline 2 & $0.1 \mathrm{~N} \mathrm{HCl}$ & $7.54 \pm 3.1$ & $77.82 \pm 1.5$ & $69.23 \pm 2.7$ & $65.08 \pm 2.2$ \\
\hline
\end{tabular}

\section{Saturation solubility studies}

Saturated solubility studies for EFV and SDs in different media (Fig. 7) showed that solubility of SDs increase with increasing polymer proportion. The improved solubility of the drug may be due to its entrapment within the carrier during the solvent evaporation process, or due to the molecularly dispersed form of the drug in the solid dispersion. Also the drug is converted into amorphous state and its wetting property is improved due to presence of hydrophilic polymer which leads to improvement in solubility. [12] The SD1 (1:1) showed an almost 7 fold increase in solubility in water, 8 fold increase in $0.1 \mathrm{~N}$ $\mathrm{HCl}$ as compared to plain EFV. SD2 (1:0.75) and SD3 (1:0.5) also displayed higher solubility than plain drug however the increase was not very significant. [17, 29]

\section{In-vitro dissolution of solid dispersions}

The in-vitro dissolution studies revealed that dissolution rate of solid dispersions was higher as compared to that of drug alone (Fig. 8). From the study, it was found that all solid dispersions displayed higher release than plain drug. [17] SD1 showed nearly $89 \%$ release in $90 \mathrm{~min}$. SD2 and SD3 exhibited 73 and $61 \%$ release at 90 min respectively. Hence, SD1 was selected for further studies. The slower release in presence of higher polymer concentration could be attributed to the matrix forming ability of HPMC E 5 which results in slower drug diffusion through the tortuous channels formed in the matrix. [12,30] The improvement in the dissolution of the drug may be due to its entrapment within the carrier during the solvent evaporation process, or due to the molecularly dispersed state of the drug in the solid dispersion. Also the drug is converted into amorphous state and its wetting property is improved. [12, 31] Thus the cumulative effect is improvement in dissolution rate. SD1 displayed the highest increase in saturation solubility and dissolution rate; hence it was subjected to further evaluation.

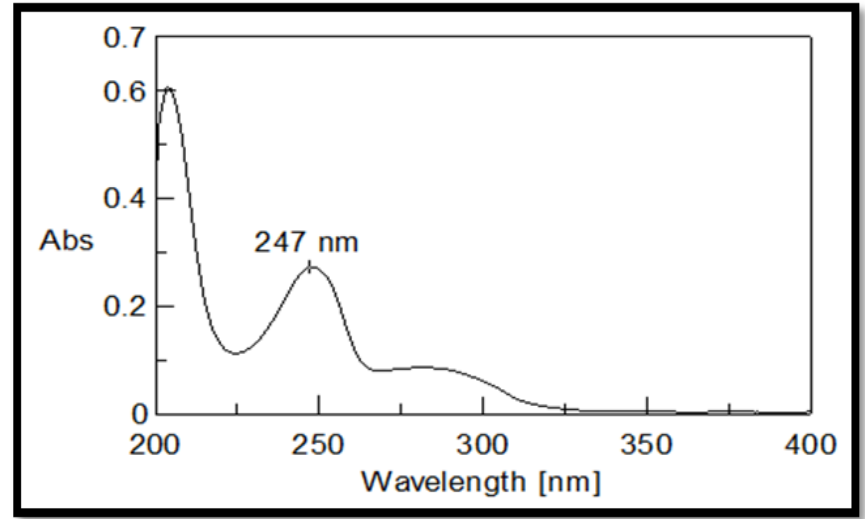

Fig. 1: UV spectrum of EFV $(10 \mu \mathrm{g} / \mathrm{ml})$ in methanol AR grade.

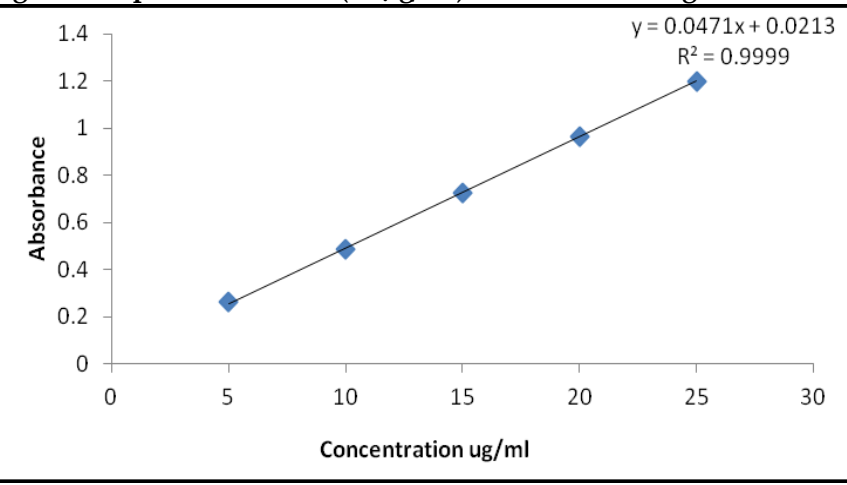

Fig. 2: Calibration curve of EFV in Methanol AR grade. (n=3, mean

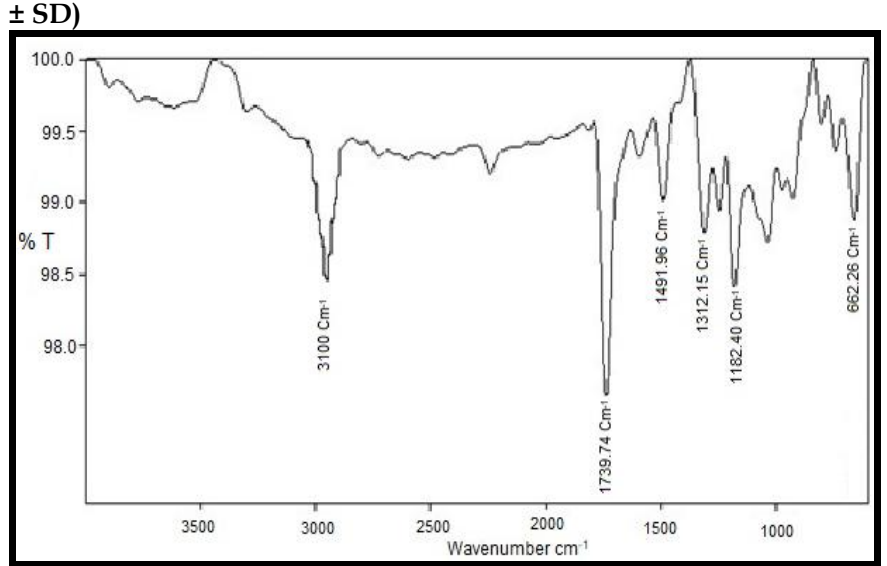

Fig. 3: FTIR Spectra of EFV.

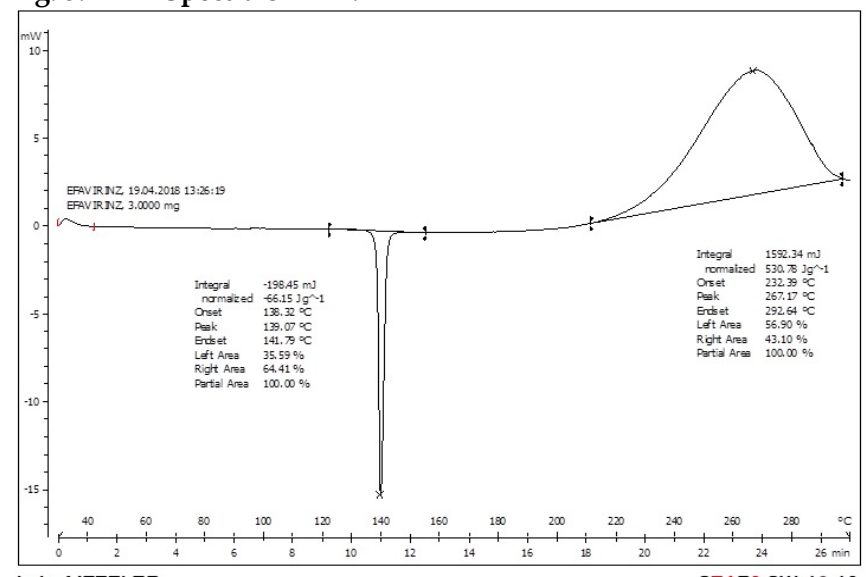

Lab: METTLER

Fig. 4: DSC thermogram of EFV. 
M Rao et al. / Formulation and Development of Gastroretentive Drug Delivery System of Efavirenz.

Table 16: Granular properties of the optimization formulations: the values represent Mean \pm S.D.

\begin{tabular}{cccccc}
\hline Formulation & Tapped density $(\mathbf{g} / \mathbf{m l})$ & Bulk density $\mathbf{( g / m l )}$ & Carr's index (\%) & Hausner's ratio (\%) & Angle of repose $(\mathbf{o})$ \\
\hline F1 & $0.65 \pm 2.9$ & $0.624 \pm 3.1$ & $4.86 \pm 3.2$ & $1.051 \pm 4.5$ & $27.75 \pm 2.1$ \\
F2 & $0.6121 \pm 2.7$ & $0.5768 \pm 2.9$ & $5.77 \pm 2.5$ & $1.061 \pm 2.5$ & $32.03 \pm 1.5$ \\
F3 & $0.5768 \pm 2.5$ & $0.5356 \pm 3.5$ & $7.14 \pm 3.2$ & $1.076 \pm 3.2$ & $27.14 \pm 1.8$ \\
F4 & $0.5769 \pm 2.2$ & $0.5454 \pm 2.4$ & $5.46 \pm 4.5$ & $1.057 \pm 3.3$ & $27.75 \pm 3.4$ \\
F5 & $0.5769 \pm 2.8$ & $0.5083 \pm 3.2$ & $11.87 \pm 4.3$ & $1.134 \pm 4.5$ & $30.22 \pm 3.7$ \\
F6 & $0.603 \pm 2.6$ & $0.5453 \pm 3.6$ & $9.55 \pm 3.8$ & $1.106 \pm 3.9$ & $31.04 \pm 2.7$ \\
F7 & $0.565 \pm 3.1$ & $0.5366 \pm 2.9$ & $5.16 \pm 3.5$ & $1.054 \pm 3.5$ & $29.02 \pm 2.9$ \\
F8 & $0.588 \pm 3.4$ & $0.5457 \pm 2.5$ & $7.27 \pm 4.1$ & $1.077 \pm 3.8$ & $27.75 \pm 3.5$ \\
F9 & $0.566 \pm 2.9$ & $0.5084 \pm 2.5$ & $10.19 \pm 4.3$ & $1.113 \pm 2.7$ & $31.42 \pm 3.2$ \\
\hline
\end{tabular}

Table 17: Experimental run \& responses for optimization of floating tablet using $3^{2}$ full factorial design

\begin{tabular}{|c|c|c|c|c|c|c|}
\hline & & Factor 1 & Factor 2 & Response $\left(\mathrm{Y}_{1}\right)$ & Response $\left(\mathrm{Y}_{2}\right)$ & Response $\left(\mathrm{Y}_{3}\right)$ \\
\hline Std & Run & A: HPMC & B: Citric acid & Lag Time & Floating Time & $\%$ Drug Release $(8 \mathrm{~h})$ \\
\hline & & Conc & Conc & Sec & Hour & $\%$ \\
\hline 5 & 1 & 21.84 & 22.5 & $70 \pm 1.6$ & $6 \pm 2.1$ & $79 \pm 1.25$ \\
\hline 1 & 2 & 19.34 & 19 & $120 \pm 1.4$ & $5 \pm 2.5$ & $72 \pm 4.62$ \\
\hline 2 & 3 & 21.84 & 19 & $125 \pm 1.4$ & $6 \pm 1.5$ & $76 \pm 2.33$ \\
\hline 8 & 4 & 21.84 & 26 & $48 \pm 1.7$ & $8 \pm 1.8$ & $85 \pm 4.6$ \\
\hline 4 & 5 & 19.34 & 22.5 & $75 \pm 2.1$ & $6 \pm 1.6$ & $77 \pm 3.33$ \\
\hline 3 & 6 & 24.34 & 19 & $121 \pm 1.6$ & $7 \pm 2.2$ & $85 \pm 1.33$ \\
\hline 7 & 7 & 19.34 & 26 & $44 \pm 2.4$ & $8 \pm 2.2$ & $89 \pm 5.3$ \\
\hline 9 & 8 & 24.34 & 26 & $41 \pm 2.7$ & $8.7 \pm 1.4$ & $89.5 \pm 2.33$ \\
\hline 6 & 9 & 24.34 & 22.5 & $68 \pm 2.5$ & $8 \pm 1.6$ & $87 \pm 5.12$ \\
\hline
\end{tabular}

Table 18: Selection of optimized batch

\begin{tabular}{cccccc}
\hline Batches & Amount of HPMC (mg) & Amount of Citric acid (mg) & Lag Time (sec) & Floating Time (h) & Cumulative \% Drug Release \\
\hline X1 & 24.34 & 26 & 40.08 & 9.083 & 90.111 \\
X2 & 24.34 & 25.88 & 40.63 & 9.02 & 89.91 \\
X3 & 24.09 & 26 & 40.92 & 8.93 & 89.39 \\
X4 & 19.34 & 26 & 45.91 & 7.91 & 88.111 \\
\hline
\end{tabular}

Table 19: Validation of batches

\begin{tabular}{|c|c|c|c|c|c|c|}
\hline \multirow{2}{*}{$\begin{array}{l}\text { Formulation } \\
\text { Code }\end{array}$} & \multicolumn{2}{|c|}{ Composition of optimized formulation } & \multirow{2}{*}{ Responses } & \multirow{2}{*}{$\begin{array}{c}\text { Predicted } \\
\text { Value }\end{array}$} & \multirow{2}{*}{$\begin{array}{l}\text { Actual } \\
\text { Value }\end{array}$} & \multirow{2}{*}{$\begin{array}{c}\% \text { Error } \\
(\%)\end{array}$} \\
\hline & Amount of HPMC (mg) & Amount of Citric acid (mg) & & & & \\
\hline \multirow{3}{*}{$\mathrm{X} 1$} & \multirow{3}{*}{24.34} & \multirow{3}{*}{26} & Lag Time & 40.08 & 41 & 2.24 \\
\hline & & & Floating Time & 9.083 & 8.7 & 4.36 \\
\hline & & & Cumulative \% Drug Release & 90.111 & 89.5 & 0.68 \\
\hline
\end{tabular}

Table 20: Evaluation of post compression parameters of optimization formulations. the values represent Mean \pm S.D.

\begin{tabular}{ccccccc}
\hline Batches & Hardness $\left.\mathbf{( k g} / \mathbf{c m}^{2}\right)$ & Diameter $\mathbf{( m m})$ & Thickness $(\mathbf{m m})$ & Friability $\mathbf{( \% )}$ & Drug content $(\mathbf{\%})$ & Weight variation $\mathbf{( g )}$ \\
\hline F1 & $8.2 \pm 2.5$ & $12.49 \pm 2.5$ & $5.16 \pm 1.8$ & $0.15 \pm 1.23$ & $99.39 \pm 1.12$ & $0.649 \pm 0.53$ \\
F2 & $8.2 \pm 3.5$ & $12.49 \pm 2.8$ & $5.16 \pm 2.5$ & $0.28 \pm 3.45$ & $99.77 \pm 2.11$ & $0.649 \pm 0.590$ \\
F3 & $8.16 \pm 3.3$ & $12.496 \pm 2.1$ & $5.16 \pm 2.8$ & $0.153 \pm 2.11$ & $98.65 \pm 2.41$ & $0.6497 \pm 0.42$ \\
F4 & $8.2 \pm 3.8$ & $12.499 \pm 2.7$ & $5.17 \pm 2.7$ & $0.153 \pm 3.77$ & $99.97 \pm 3.66$ & $0.6496 \pm 0.52$ \\
F5 & $8.19 \pm 4.2$ & $12.499 \pm 3.2$ & $5.17 \pm 3.2$ & $0.153 \pm 3.45$ & $99.9 \pm 2.41$ & $0.65 \pm 0.554$ \\
F6 & $8.16 \pm 4.5$ & $12.493 \pm 3.5$ & $5.16 \pm 4.1$ & $0.154 \pm 4.65$ & $98.85 \pm 1.45$ & $0.649 \pm 0.48$ \\
F7 & $8.2 \pm 4.3$ & $12.499 \pm 4.8$ & $5.168 \pm 4.6$ & $0.416 \pm 4.23$ & $99.83 \pm 3.55$ & $0.649 \pm 0.52$ \\
F8 & $8.2 \pm 4.2$ & $12.495 \pm 3.5$ & $5.164 \pm 2.5$ & $0.266 \pm 2.11$ & $99.55 \pm 2.25$ & $0.65 \pm 0.53$ \\
F9 & $8.16 \pm 4.8$ & $12.499 \pm 3.2$ & $5.17 \pm 2.7$ & $0.333 \pm 2.56$ & $99.94 \pm 4.45$ & $0.649 \pm 0.53$ \\
\hline
\end{tabular}

Table 21: Stability data

\begin{tabular}{|c|c|c|c|c|}
\hline $\begin{array}{c}\text { Formulation } \\
\text { F8 }\end{array}$ & 0 Month & $1^{\text {st }}$ Month & $2^{\text {nd }}$ Month & $3^{\text {rd }}$ Month \\
\hline $\begin{array}{l}\text { Hardness } \\
(\mathrm{kg} / \mathrm{cm} 2)\end{array}$ & $8.2 \pm 0.0$ & $8.2 \pm 0.0$ & $8.1 \pm 0.0001$ & $8.1 \pm 0.0001$ \\
\hline $\begin{array}{c}\text { Drug content } \\
(\%)\end{array}$ & 99.57 & 99.49 & 99.49 & 99.46 \\
\hline $\begin{array}{c}\text { Buoyancy lag } \\
\text { time (sec) }\end{array}$ & 40 & 40 & 42 & 44 \\
\hline $\begin{array}{l}\text { Floating time } \\
\text { (h) }\end{array}$ & $>12$ & $>12$ & $>12$ & $>12$ \\
\hline
\end{tabular}

\section{Differential Scanning Calorimetry}

The DSC thermograms of EFV showed in (Fig. 9), shows a sharp endothermat $147^{\circ} \mathrm{C}$ (melting point), indicating the crystalline nature of thedrug. The drug peak in SD1 has shifted due to its dilution effects which points to amorphization of the drug and is molecularly dispersed in the polymer matrix which supports the FTIR results. ${ }^{[32]}$ Amorphization of the drug could be another reason for enhanced solubility and dissolution rate of poorly water soluble drug. [17]

FT-IR studies of solid dispersions

The key peaks of EFV was observed (Fig. 10) in the region of $1749.7 \mathrm{~cm}^{-1}$ due to the $\mathrm{C}=\mathrm{O}$ aliphatic stretching, a peak at $1500.83 \mathrm{~cm}^{-1}$ due to $\mathrm{C}=\mathrm{C}$ stretching and a peak at $3100 \mathrm{~cm}^{-1}$ due to aliphatic N-H stretching. The broadening of the peak in the spectra of SD1 indicates that EFV is molecularly dispersed in the polymer matrix. However other peaks related to C-O$\mathrm{C}, \mathrm{N}-\mathrm{H}, \mathrm{C}=\mathrm{C}$ stretching remains unchanged. This indicates that overall stereochemistry of the molecule might not be significantly changed. [17] 


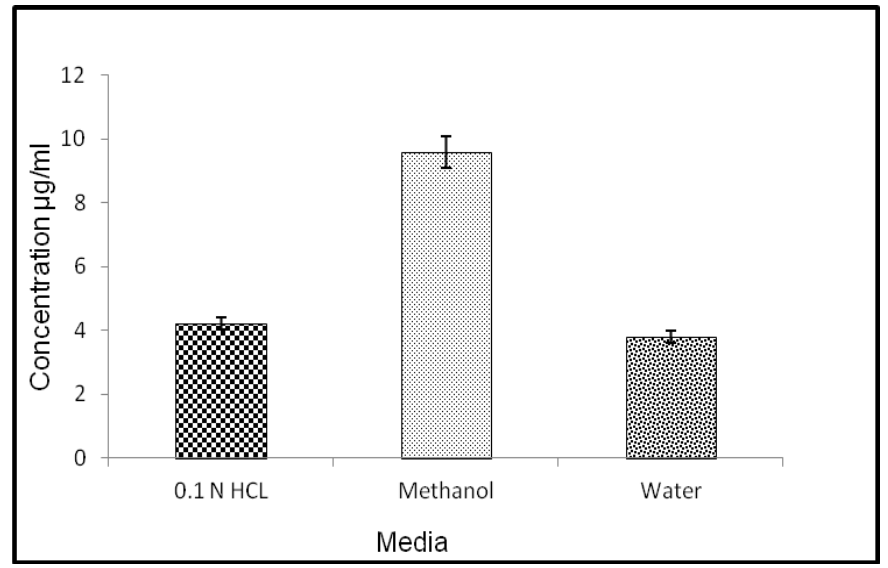

Fig. 5: Solubility of EFV in various solvents such as $\mathrm{HCl}$, methanol, water. $(n=3$, mean $\pm S D)$

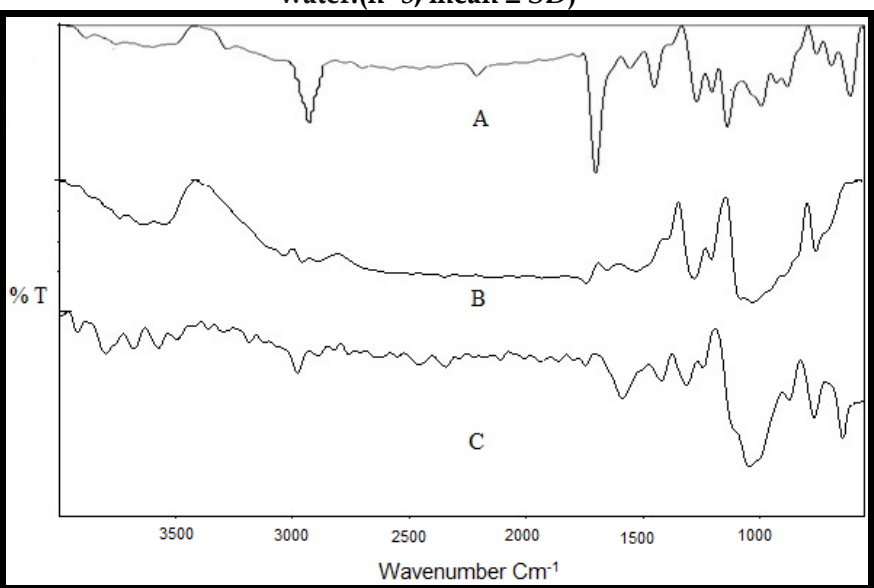

Fig. 6: FTIR spectra (after 30 days) for drug-excipients compatibility studies. $\mathbf{A}=\mathrm{EFV}, \mathbf{B}=\mathrm{EFV}+\mathrm{HPMC}, \mathbf{C}=\mathrm{EFV}+\mathrm{NaCMC}$

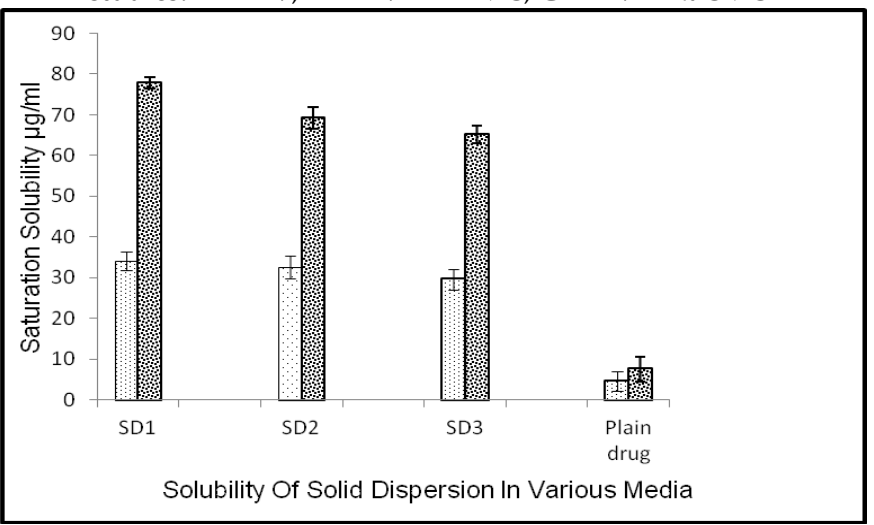

Fig. 7: Saturation solubility in different media i.e., $0.1 \mathrm{~N} \mathrm{HCl}$ and water. Mean \pm SD $(n=3)$

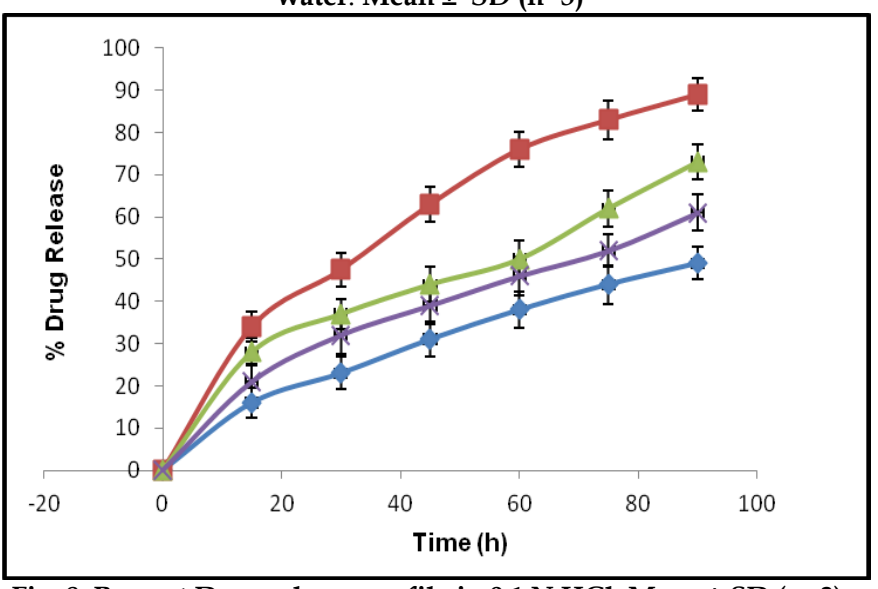

Fig. 8: Percent Drug release profile in 0.1 N HCl. Mean \pm SD $(n=3)$, $\sim$ Drug, - SD1, - SD2, $\leftarrow$ SD3.

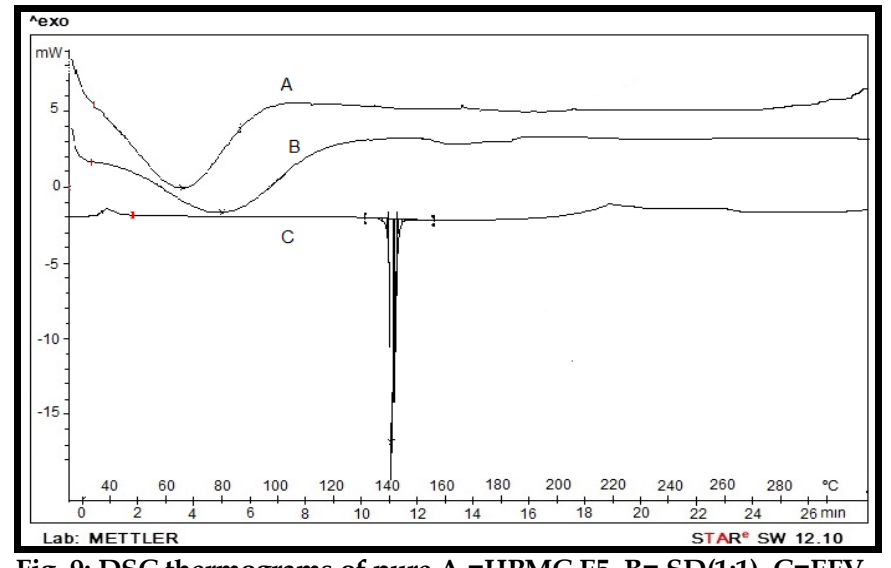

Fig. 9: DSC thermograms of pure $A=H P M C ~ E 5, B=S D(1: 1), C=E F V$.

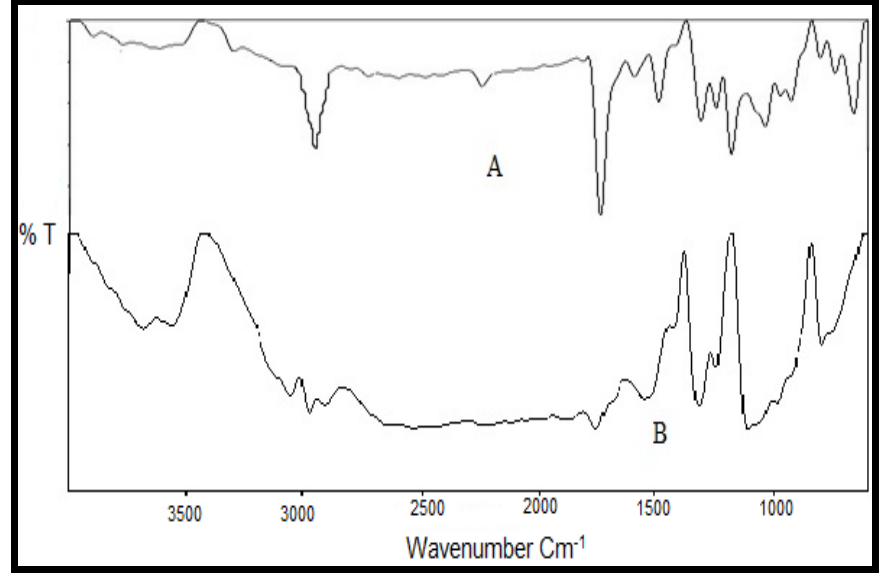

Fig. 10: FTIR spectra for compatibility studies. A= EFV, B = Solid dispersion

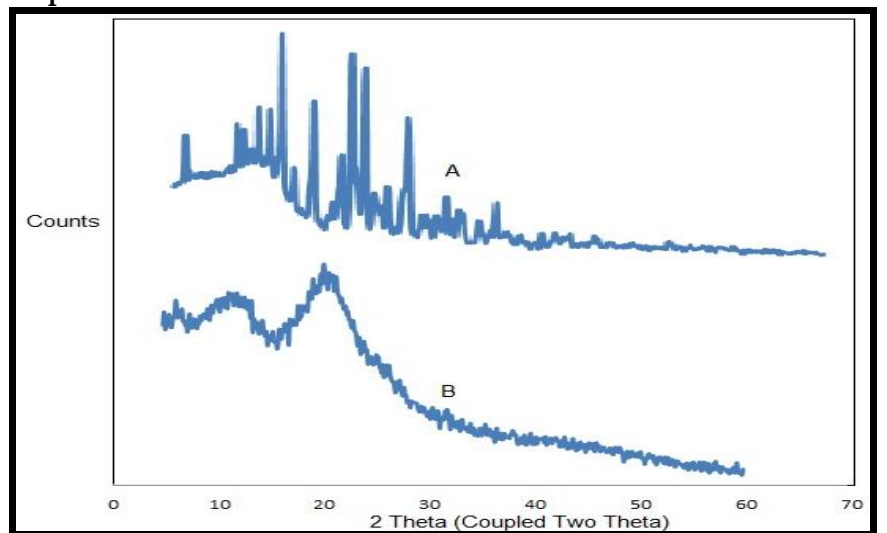

Fig. 11: Powder X-ray diffraction patterns of $A=$ plain drug, $B=$ solid dispersion.

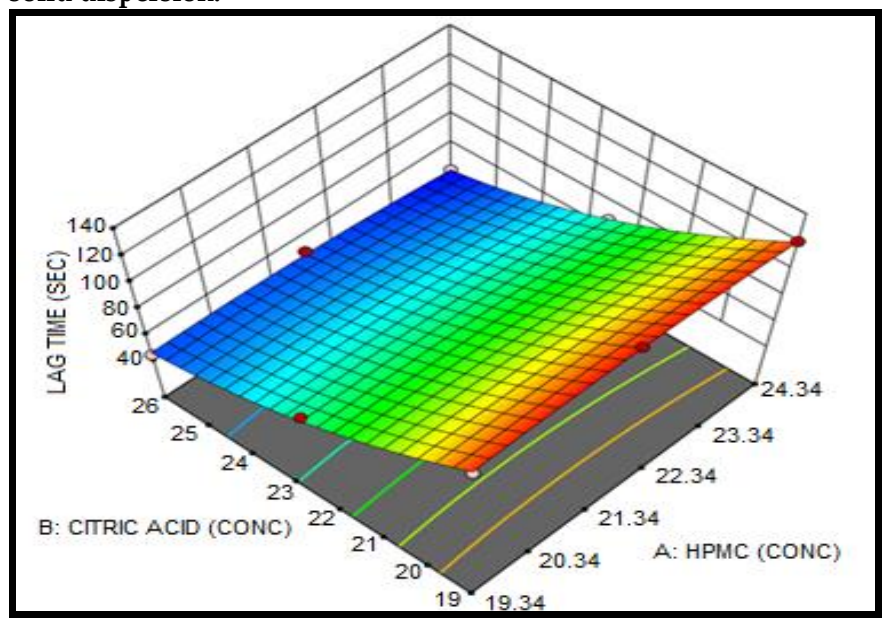

Fig. 12: Response surface plot (3D) showing the effect of HPMC \& citric acid on lag time. $(n=3$, mean $\pm S D)$ 


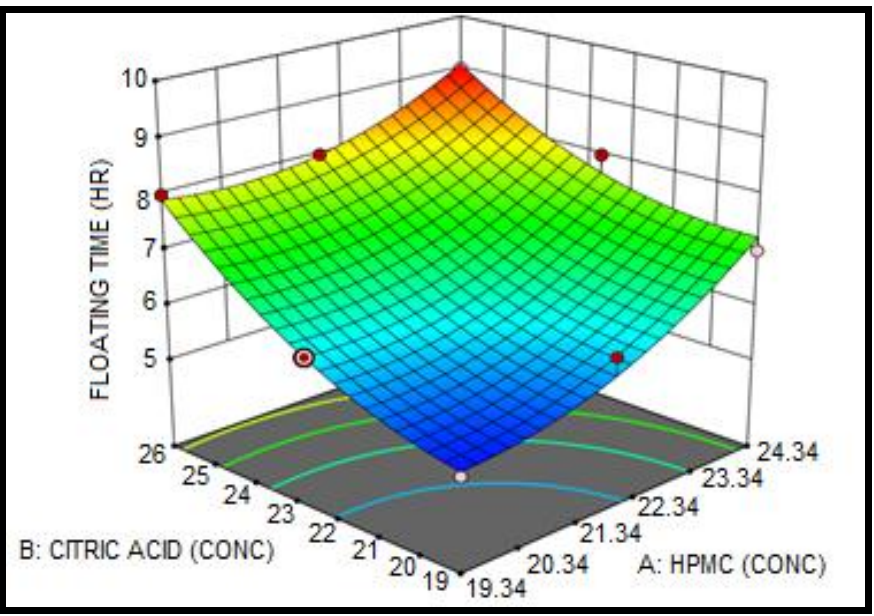

Fig. 13: Response surface plot (3D) showing the effect of HPMC \& citric acid on floating time. $(\mathrm{N}=3$, mean $\pm S D)$

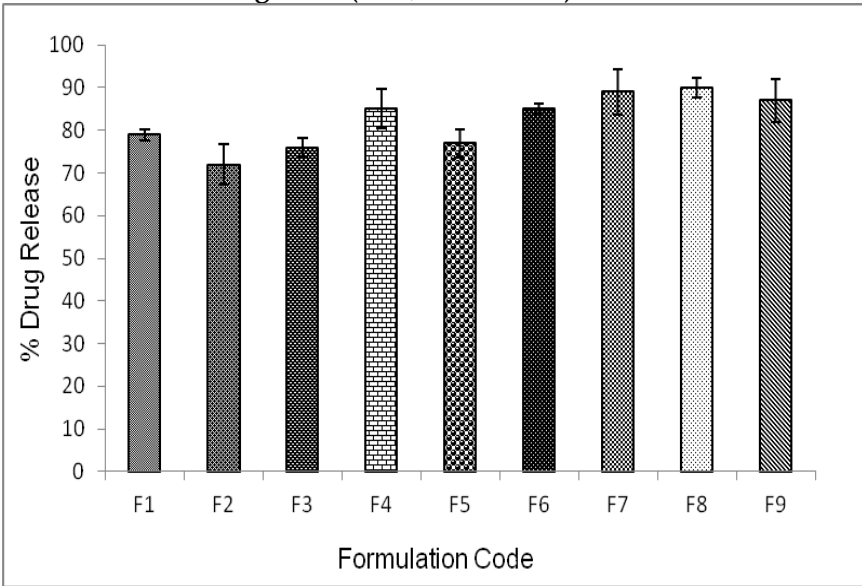

Fig. 14: In vitro drug release data of optimization formulation (in 8 h). The values represent mean \pm S.D

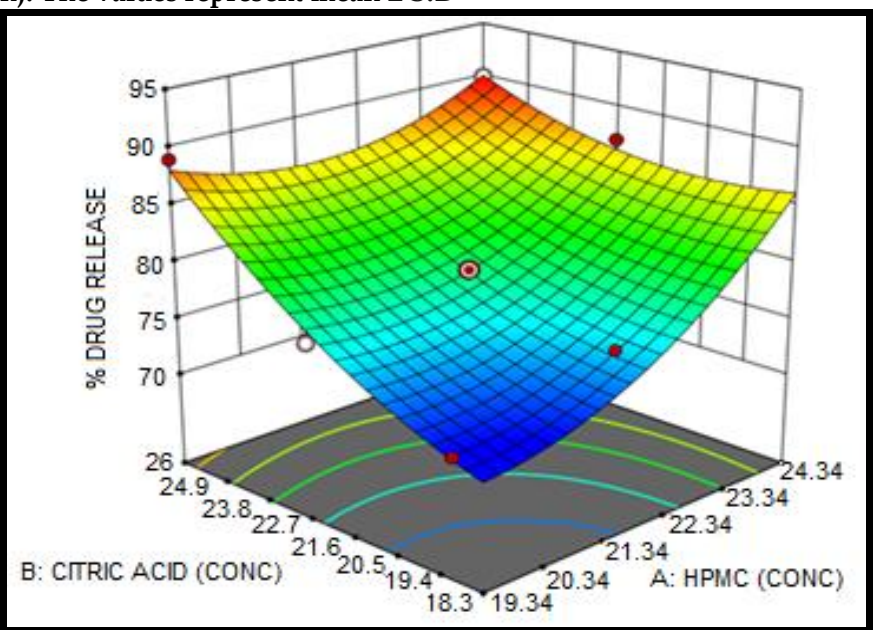

Fig. 15: Response surface plot (3D) showing the effect of HPMC \& citric acid on $\%$ drug release $(N=3$, mean $\pm S D$ )

\section{Powder X-Ray diffraction patterns}

The PXRD of EFV consist of sharp multiple peaks at $2 \theta$ angles of $6^{\circ}, 10.31^{\circ}, 12^{\circ}, 15^{\circ}$ and $17^{\circ}, 20^{\circ}, 22^{\circ}, 24^{\circ}, 28^{\circ}$, indicating crystalline nature of the drug. The diffractogram of SD1 exhibited a halo pattern with reduced peak intensities. [17] Generally this partial loss of crystallinity supports DSC results and confirms partial amorphization of the drug. ${ }^{[33]}$

Evaluation of floating tablet

SD1 ratio of solid dispersion was selected based on percent drug release and drug content and further used for the formulation of gas generating floating tablets. [5] HPMC K100, a water soluble polymer was selected as a hydrophilic matrix. Citric acid and sodium bicarbonate were used as the gas generating agents. The solid dispersion and all other ingredients were separately passed through sieve \# 60 and triturated to ensure thorough mixing. Then ethanolic solution containing PVP K30 was added drop wise to above mixture \&the wet mass was passed through sieve no 18 and granules so obtained were dried and lubricated with talc and compressed using $12 \mathrm{~mm}$ punch and die (Rimek Mini Press-II MT). [23, 25]

\section{Pre compression parameters}

The bulk density and tap density values of the powder ranged from $0.50 \pm 3.2 \mathrm{~g} / \mathrm{ml}$ to $0.62 \pm 3.1 \mathrm{~g} / \mathrm{ml}$ and 0.56 $\pm 3.1 \mathrm{~g} / \mathrm{ml}$ to $0.65 \pm 2.9 \mathrm{~g} / \mathrm{ml}$. Moreover, powders having Carr's index below 15 were considered to have good flow properties and could be successfully compressed into tablets with uniform weight. [30] Angle of repose ranged from $27.14 \pm 1.8$ to $32.03 \pm 1.5$ which indicates excellent flow properties and Hausner's ratio below 1.15 which indicates excellent flow properties with less interparticle frictions between particles. ${ }^{[18]}$ The granular properties like bulk density, tapped density, Carr's index, Hausner's ratio and angle of repose for all formulations were determined and the results are reported as shown in the (Table 15).

\section{Experimental design}

For formulation of floating tablets as per $3^{2}$ full factorial design the concentrations of citric acid and HPMC K100 were considered as the two independent factors. Design comprised of 9 experimental runs to evaluate the significance of individual and combined effects of the citric acid and HPMC K100 on floating time, lag time and percent drug release in $8 \mathrm{~h}$. The response data for the factorial design trials were fitted in the $3^{2}$ factorial design to get model equations for responses analysed. [34] Quantitative effect of independent variable in the obtained equation are mean results obtained by changing one factor from its low to high value keeping another factor constant. The polynomial equations obtained were visualized with the help of 3D response surface graphs. [25,34]

\section{Characterization of factorial batches}

Lag Time (Y1)

Lag time is one of the important characteristics in floating gastroretentive formulations and it is the time taken by tablet to emerge on surface of media. When citric acid liberated $\mathrm{CO}_{2}$ after reaction with gastric acid, the combination of effervescence and swelling of the polymer enables the dosage form to achieve lower density than the gastric fluid i.e, $(1.004$ to $1.010 \mathrm{~g} / \mathrm{ml})$ and results in an upward motion of the tablet which maintains the buoyancy. The floating time and percent drug release is dependent on lag time. $[8,4]$

Lag time $=73.00+1.67 \mathrm{~A}-39.00 \mathrm{~B}-1.25 \mathrm{AB}-3.00 \mathrm{~A}^{2}+$

\section{$12.00 \mathrm{~B}^{2}$}

\section{Equation 1}

The lag time of factorial batches was found to be between 40 to $125 \mathrm{sec}$. The linear effect of the amount of 
(B) was found to be significant $(p<0.05)$. The negative coefficient implied that an increase in the amount of Citric acid (B) led to a decrease in lag time (Y1). In contrast, the quadratic effect of amount of Citric acid $\left(\mathrm{B}^{2}\right)$ was found to be significant $(p<0.05)$ having negative coefficient. Though the effect of the amount of HPMC K 100 (A) was found to be significant $(p<0.05)$ with positive coefficient (Eq.1), indicating an increase in lag time (Y1) with an increase in the amount of HPMC $\mathrm{K}$ 100(A). The high negative coefficient for term AB $(p<0.05)$ indicated interaction between HPMC K 100 and citric acid. This implied that a judicious selection of the amount of HPMC K 100 and Citric acid is essential to ensure stability, and decrease in lag time.

\section{Floating Time (Y2)}

Floating time is the time span for which the dosage form remains on surface of medium. Effervescence, due to reaction between sodium bicarbonate and gastric medium, besides citric acid in the formulation caused $\mathrm{CO}_{2}$ to get entrapped in the swelling polymer to improve the floating time. $[8,4]$

\section{Floating time $=6.33+0.8333 \mathrm{~A}-1.17 \mathrm{~B}-0.2500 \mathrm{AB}+$} $0.5000 \mathrm{~A}^{2}-0.5000 \mathrm{~B}^{2}$......Equation 2

The floating time of factorial batches was found to be between 5 to $9 \mathrm{~h}$. The linear effect of the amount of (B) was found to be significant $(p<0.05)$. The negative coefficient implied that an increase in the amount of Citric acid (B) led to increase in floating time (Y2). In contrast, the quadratic effect of amount of Citric acid $\left(\mathrm{B}^{2}\right)$ was found to be significant $(p<0.05)$ having negative coefficient. Though the effect of the amount of HPMC K 100 (A) was found to be significant $(p<0.05)$ with positive coefficient (Eq.2), indicating an increase in floating time (Y2) with an increase in the amount of HPMC K 100 (A). The high negative coefficient for term $\mathrm{AB}(p<0.05)$ indicated interaction between HPMC K 100 and citric acid. This implied that a judicious selection of the amount of HPMC K 100 and citric acid is essential to ensure stability, and increase in floating time. [27-28]

Percent Cumulative Drug Release at 8 Hours (Y3)

The gastric contents and citric acid releases carbon dioxide $\left(\mathrm{CO}_{2}\right)$ by reacting with sodium bicarbonate which becomes trapped within the gellified hydrocolloid system. The combination of effervescence and swelling causes floatation of the tablet for extended time period and ensures slow release of the drug. [34]

\% Drug Release $=172.29-13.98 \mathrm{~A}+2.22-0.34 \mathrm{AB}-$ $0.533 \mathrm{~A}^{2}+0.1496 \mathrm{~B}^{2}$......Equation 3

The cumulative percent release of factorial batches was found to be between 72 to $89.5 \%$ in $8 \mathrm{~h}$. The linear effect of the amount of (A) was found to be significant $(p<0.05)$. The negative coefficient implied that an increase in the amount of HPMC K 100 (A) led to increase in percent drug release $(\mathrm{Y} 3)$. In contrast, the quadratic effect of amount of HPMC K $100\left(\mathrm{~A}^{2}\right)$ was found to be significant $(p<0.05)$ having negative coefficient. Though the effect of the amount of HPMC K 100 (A) was found to be significant $(p<0.05)$ with positive coefficient (Eq.3), indicating an increase in percent drug release (Y3) with an increase in the amount of HPMC K 100 (A). The high negative coefficient for term $\mathrm{AB}(p<0.05)$ indicated interaction between HPMC K 100 and citric acid. This implied that a judicious selection of the amount of HPMC K 100 and Citric acid is essential to ensure stability, and increase in percent drug release.

Selection of optimized formulation and validation studies

Selection of optimized formulation of floating tablet was carried out; where the various trials were made to attain the goals like minimization of lag time and maximization of floating time and cumulative percent drug release. The optimized batch was chosen by numeric optimization using the desirability function. The constraints set for numerical optimization of floating tablet included lag time ( $\mathrm{Y} 1<180 \mathrm{sec})$, floating time $(\mathrm{Y} 2>8 \mathrm{~h})$ and cumulative percent drug release (Y3> 90\%). Based on these three responses (Y1, Y2 and Y3), there were four different optimized batches of floating tablet given by the software and among these four batches of floating tablet, one batch was selected as an optimized batch of floating tablet based on their desirability function. Validation of the optimization methodology by comparing the observed responses with those of the predicted responses understood that percent prediction error for both the responses (Y1, Y2 and Y3) ranged between $0.98 \%$ and $0.99 \%$ of floating tablet. Thus, the formulation batch giving minimum lag time (Y1), maximum floating time (Y2) and the maximum cumulative percent drug release (Y3) was chosen as the optimized batch.

Post compression evaluation

The tablets weighing above $650 \mathrm{mg}$ have the limit of $\pm 5 \%$ variation according to Indian Pharmacopoeia. [35] The weight variation was within specified limits. The hardness of the tablet was found to be between 8.00 to $8.2 \mathrm{~kg} / \mathrm{sq} \mathrm{cm}$. The thickness was between $5.16 \mathrm{~mm}$ to $5.17 \mathrm{~mm}$. The friability of the tablets was found to be less than $1 \%$ which was considered within the limit. [26] These two parameters gives a measure of the strength of the tablets during handling, packaging and shipping. The percentage drug content estimations showed values in the range of $98.65 \pm 2.41 \%$ to $99.97 \pm 3.66 \%$ which reflects content uniformity in different formulations. [27] The average percentage weight variation of each formulation remained within $\pm 5 \%$ and hence all formulations pass the test for uniformity of weight as per I.P. [35]

\section{Stability studies}

The stability studies conducted as per ICH guidelines revealed that there is no change in physical appearance, hardness, drug content and floating lag time.

The authors conclude that the development of gastroretentive drug delivery system with enhanced solubility can improve the therapeutic benefits of EFV. SDs of EFV prepared by a solvent evaporation method showed enhanced drug dissolution in comparison with pure drug. FTIR and DSC studies showed absence of 
interaction between the drug and carrier. PXRD study confirmed amorphization of drug. Further the optimized batch of gas generating floating tablet consist of Citric acid and HPMC K100 which results in desirable lag time, floating time and percent drug release. From the in vitro studies, it was also shows that there was an increase in the solubility.

\section{ACKNOWLEGDEMENTS}

Authors are thankful to A.I.S.S.M.S. College of Pharmacy, Pune, for providing the required facilities for the research work.

\section{REFERENCES}

1. Shaha SH, Patel JK, Pundarikakshudu K. An overview of a gastroretentive floating drug delivery system. Asian J Pharm Sci 2009;4:65-80.

2. Nayak AK, Maji R, Das B. Gastroretentive drug delivery systems: a review. Asian J Pharma Clinical Res. 2010; 3(1):210

3. Moes AJ. Gastroretentive dosage forms. Crit Rev Ther Drug Carrier Syst. 1993;10:143-195.

4. Baumgartner S, Kristl J, Vrecer F. Optimization of floating matrix tablets and evaluation of their gastric residence time. Int J Pharm. 2000;195:125-135.

5. Hoffman A. Pharmacodynamic aspects of sustained release preparations. Adv Drug Deliv Rev. 1998;33:185-199.

6. Klausner EA, Lavy E, Friedman M, et al. Expandable gastroretentive dosage forms. J Control Release. 2003;90:143162

7. Rouge N, Allemann E, Gex-Fabry M, et al. Comparative pharmacokinetic study of a floating multiple-unit capsule, a high-density multiple-unit capsule and an immediate release tablet containing $25 \mathrm{mg}$ atenolol. Pharm Acta Helv. 1998;73:81-87.

8. Singh BN, Kim KH. Floating drug delivery systems: an approach to oral controlled drug delivery via gastric retention. J Control Release. 2000;63:235-239.

9. https://www.medinstitute.org/sti-wizard/hiv 17/6/2019.

10. http://pubchem.ncbi.nlm.nih.gov/compound/efavirenz\#sec tion=Depositor-Supplied-Synonyms.(access date: 25/06/2018)

11. Chiou WL, Riegalman S. Pharmaceutical Applications Of Solid Dispersion Systems. J Pharm Sci1971;60:1281-1302.

12. Patil AN, Shinkar DM, Saudagar RB. Review Article: Solubility Enhancement by Solid Dispersion. Int J Curr Pharm Res. 9(3): 15-18.

13. Shinde SS, Shete AS, PatilMV, SalunkheS, Indapure D. Preparation \& Physicochemical Characterization Of Poorly Water Soluble Drug By Using Spray Drying And Solvent Evaporation Methods. Int J Pharma Sci Res. 2014; 5(3): 10351044.

14. Das SK, et al. Solid Dispersions: An Approach to Enhance the Bioavailability of Poorly Water-Soluble Drugs. Int J Pharmaco and Pharma Tech. 2011;1(1): 2277-3436.

15. Meka L, Vobalaboine V. Enhancement of solubility and dissolution rate of poorly water soluble drugs using cosolvency and solid dispersion techniques. Int J Pharm Sci Nanotech 2009;1:349-56.

16. Mogal SA, et al. Solid dispersion technique for improving solubility of some poorly soluble drugs. Der Pharmacia Lettre. 2012; 4(5): 1574-1586.
17. Rao M, et al. Dissolution Improvement of Simvastatin by Surface Solid Dispersion Technology. Dissolution Technologies. 2010; 27-34.

18. Reddy BV, Ramana Murthy KV. Enhancement Of Dissolution Rate Of Efavirenz By Solid Dispersion Technique. Int J Pharm Bio Sci. 2012; 2( 2):185-190.

19. Ganapuram BR, et al. Development, evaluation and characterization of surface solid dispersion for solubility and dispersion enhancement of irbesartan. J Pharmacy Res. 2013; 472-477.

20. Chan S, et al. The characterization and dissolution performances of spray dried solid dispersion of ketoprofen in hydrophilic carriers. As J Pharma Sci. 2015; 10: 372-385.

21. Guleria R, et al. Polyethylene Glycol Enhances Solubility of Domperidone Through Solid Dispersion. Am J Pharmtech Res. 2012; 2(2): 630-638.

22. Bhole PG, Patil VR. Enhancement of water solubility of felodipine by preparing solid dispersion using poly-ethylene glycol 6000 and poly-vinyl alcohol. As J Pharm. 2009; 240-244.

23. Shinde AJ, Harinath MN. Gastroretentive Drug Delivery System: An Overview. 2008;6(1):1-12.

24. Begum MY, Avanthi J, Shwetha A, Madhuri T, Sudhakar M and Naveen D, Formulation And Evaluation Of Sustained Release Floating Tablets Of Loratadine. Int J Pharma Sci and Res. 2014;5(10): 4375-4385.

25. Patel GM, Patel HR, Patel M. Floating Drug Delivery System: An Innovative Approach to Prolong Gastric Retention. Pharmainfo.net 2007;5(6).

26. Shirwalkar AA, Kumar SMR, Jacobs. Recent developments in floating drug delivery systems for gastric retention of drugs. An overview. Ind Drugs 2006;43(9):697-704.

27. Charyulu NR, et al. Formulation and evaluation of bilayer floating tablets of Diltiazem hydrochloride for bimodal release. Int J Res Pharm Sci. 2012;3(2):301-306.

28. Gambhire MN, et al. Development and In Vitro Evaluation of an Oral Floating Matrix Tablet Formulation of Diltiazem Hydrochloride. AAPS Pharm Sci Tech 2007; 8 (3) E1-E9.

29. Nipun TS, Islam SA. SEDDS of gliclazide: Preparation and characterization by in-vitro, ex-vivo and in-vivo techniques. Saudi pharma J. 2014;22(4):343-348.

30. Bhusnure OG, Kazi PA, Gholve SB, Ansari A, Kazi SN. Solid Dispersion: An Ever Green Method for Solubility Enhancement of Poorly Water Soluble Drugs. Int J Res Pharm chem. 2014;4(4):906-918.

31. Kumari B, Bishnoi HK. Solid Dispersion: Its Types and Mechanism of Enhancement of Solubility by Solid Dispersion. J Pharm Res. 2019;8(3):65-71.

32. Gomes EC et al., A Chemical Interactions Study of Antiretroviral Drugs Efavirenz and Lamivudine Concerning the Development of Stable Fixed-Dose Combination Formulations for AIDS Treatment. J BrazChem Soc. 2013; 24(4): 573-579.

33. Kolhe S, Chaudhari P, More D. Dissolution Enhancement of Poorly Water Soluble Efavirenz by Hot Melt Extrusion Technique. Int. J. Drug Dev. \& Res. 2013;5(2): 368-381.

34. Senjoti FG, Mahmood S, Jaffri JM, et al. Design and in-vitro evaluation of sustained release floating tablets of metformin $\mathrm{HCl}$ based on effervescence and swelling. Iran J Pharm Res. 2016;15:53-70.

35. Indian Pharmacopoeia 2010, Govt of India, Ministry of health and family welfare. Delhi: Indian Pharmacopoeial Commission, Ghaziabad, 2010. 